Applied Radiation and Isotopes - Short Communication

\title{
Imaging quality of ${ }^{44} \mathrm{Sc}$ in comparison with five other PET radionuclides using Derenzo phantoms and preclinical PET
}

Maruta Bunka ${ }^{1,2 \dagger}$, Cristina Müller ${ }^{3 \dagger^{* *}}$, Christiaan Vermeulen ${ }^{3}$, Stephanie Haller ${ }^{3}$, Andreas Türler ${ }^{1,2}$, Roger Schibli ${ }^{3,4}$, Nicholas P. van der Meulen ${ }^{1,3^{*}}$

${ }^{1}$ Laboratory of Radiochemistry and Environmental Chemistry, Paul Scherrer Institute, Villigen-PSI, Switzerland

${ }^{2}$ Laboratory of Radiochemistry and Environmental Chemistry, Department of Chemistry and Biochemistry University of Bern, Bern, Switzerland

${ }^{3}$ Center for Radiopharmaceutical Sciences ETH-PSI-USZ, Paul Scherrer Institute, Villigen-PSI, Switzerland

${ }^{4}$ Department of Chemistry and Applied Biosciences, ETH Zurich, Zurich, Switzerland

${ }^{\dagger}$ contributed equally to this manuscript

* Corresponding authors:

Dr. Nicholas van der Meulen and Dr. Cristina Müller

Laboratory of Radiochemistry and Environmental Chemistry

Center for Radiopharmaceutical Sciences ETH/PSI/USZ

Paul Scherrer Institute

5232 Villigen-PSI

Switzerland

e-mail: nick.vandermeulen@psi.ch, cristina.mueller@psi.ch

phone: +41-56-310 50 87, +41-56-310 4454

fax: $\quad+41-56-3102843$

Abbreviated Title: Comparative PET phantom study

Keywords: phantom, PET, resolution, ${ }^{11} \mathrm{C},{ }^{18} \mathrm{~F},{ }^{68} \mathrm{Ga},{ }^{44} \mathrm{Sc},{ }^{64} \mathrm{Cu},{ }^{89} \mathrm{Zr}$ 


\section{ABSTRACT}

PET is the favored nuclear imaging technique because of the high sensitivity and resolution it provides, as well as the possibility for quantification of accumulated radioactivity. ${ }^{44} \mathrm{Sc}\left(\mathrm{T}_{1 / 2}=3.97 \mathrm{~h}\right.$, $\mathrm{E} \beta^{+}=632 \mathrm{keV}$ ) was recently proposed as a potentially interesting radionuclide for PET. The aim of this study was to investigate the image quality, which can be obtained with ${ }^{44} \mathrm{Sc}$, and compare it with five other, frequently employed PET nuclides using Derenzo Phantoms and a small-animal PET scanner. The radionuclides were produced at the medical cyclotron at CRS, ETH Zurich $\left({ }^{11} \mathrm{C},{ }^{18} \mathrm{~F}\right)$, at the Injector II research cyclotron at CRS, PSI $\left({ }^{64} \mathrm{Cu},{ }^{89} \mathrm{Zr},{ }^{44} \mathrm{Sc}\right)$, as well as via a generator system $\left({ }^{68} \mathrm{Ga}\right)$. Derenzo phantoms, containing solutions of each of these radionuclides, were scanned using a GE Healthcare eXplore VISTA small-animal PET scanner. The image resolution was determined for each nuclide by analysis of the intensity signal using the reconstructed PET data of a hole-diameter of $1.3 \mathrm{~mm}$. The image quality of ${ }^{44} \mathrm{Sc}$ was compared to five frequently used PET radionuclides. In agreement with the positron range, an increasing relative resolution was determined in the sequence of ${ }^{68} \mathrm{Ga}<{ }^{44} \mathrm{Sc}<{ }^{89} \mathrm{Zr}<{ }^{11} \mathrm{C}<{ }^{64} \mathrm{Cu}<{ }^{18} \mathrm{~F}$. The performance of ${ }^{44} \mathrm{Sc}$ was in agreement with the theoretical expectations based on the energy of the emitted positrons.

Key Words: PET; ${ }^{18} \mathrm{~F} ;{ }^{64} \mathrm{Cu} ;{ }^{11} \mathrm{C} ;{ }^{89} \mathrm{Zr} ;{ }^{44} \mathrm{Sc} ;{ }^{68} \mathrm{Ga}$; Derenzo phantom; FWHM; resolution 


\section{Introduction}

Current clinical PET is the favored method of nuclear physicians because of the high sensitivity and resolution it provides, as well as the possibility for quantification of accumulated radioactivity (Mittra and Quon, 2009; Rahmim and Zaidi, 2008). The resolution of the reconstructed image is mainly dependent on (i) detector-specific effects, (ii) photon non-collinearity and the (iii) positron range of the employed PET nuclide (Rahmim and Zaidi, 2008). Detector-specific effects (e.g. size and geometry) are dependent on the type of PET scanner employed. Non-collinearity originates from the fact that the two $511 \mathrm{keV}$ photons are not emitted precisely in opposite $\left(180^{\circ}\right.$-angle) directions. The corresponding resolution blurring depends on the ring diameter and is, therefore, of minor importance in the case of small-animal PET, but may be of relevance for clinical PET (Rahmim and Zaidi, 2008). The third factor is the positron range, defined as the average direct distance which the positron travels from the decaying atom to the location of the annihilation process. Since this parameter is a function of the positron energy, it varies among different radionuclides. The higher the positron energy of a PET radionuclide, the more pronounced is the degradation of the image resolution, especially in smallanimal PET (Rahmim and Zaidi, 2008).

The most widely used PET radionuclides are the pure positron-emitters ${ }^{18} \mathrm{~F}$ and ${ }^{11} \mathrm{C}$, which can be produced at medical cyclotrons (Table 1) (Kramer-Marek and Capala, 2012). The most important PET radiotracer is $2-\left[{ }^{18} \mathrm{~F}\right]$ fluoro-2-deoxy-D-glucose $\left(\left[{ }^{18} \mathrm{~F}\right] \mathrm{FDG}\right)$ which has been used for almost four decades for the imaging of cancer and inflammatory diseases (Basu and Alavi, 2008). In recent times, positron-emitting radiometals have also been increasingly introduced in clinical practice (KramerMarek and Capala, 2012; Laforest and Liu, 2008). ${ }^{68} \mathrm{Ga}$ is obtained from a ${ }^{68} \mathrm{Ge} /{ }^{68} \mathrm{Ga}$ generator and, due to its short half-life, it is suitable mainly for the labeling of small molecules and peptides with fast pharmacokinetics (Table 1) (Eiber et al., 2015; Gabriel et al., 2007). Other interesting cyclotronproduced radiometals are ${ }^{64} \mathrm{Cu}$ and ${ }^{89} \mathrm{Zr}$, which have been widely used pre-clinically, as well as in clinics (Table 1) (Anderson and Ferdani, 2009; Dijkers et al., 2010).

More recently, ${ }^{44} \mathrm{Sc}$ has attracted the attention of researchers and physicians because of its excellent characteristics for PET imaging (Table 1) (Roesch, 2012). The production of ${ }^{44} \mathrm{Sc}$ has been proposed via a ${ }^{44} \mathrm{Ti} /{ }^{44} \mathrm{Sc}$-generator (Roesch, 2012) or by irradiation of natural or enriched $\mathrm{Ca}$ targets at a 
cyclotron (Krajewski et al., 2013; Müller et al., 2013; Severin et al., 2012). It has been recently demonstrated that cyclotron-produced ${ }^{44} \mathrm{Sc}$ can be made available in sufficient quantities for clinical application (van der Meulen et al., 2015). ${ }^{44} \mathrm{Sc}$ may, therefore, be an attractive alternative to the currently-used ${ }^{68} \mathrm{Ga}$ due to its almost four-fold longer half-life which allows transportation of ${ }^{44} \mathrm{Sc}$ radiopharmaceuticals to hospitals remote from PET centers containing a cyclotron (van der Meulen et al., 2015).

\section{Table 1}

While ${ }^{11} \mathrm{C},{ }^{18} \mathrm{~F},{ }^{64} \mathrm{Cu},{ }^{89} \mathrm{Zr}$ have been investigated and compared in detail by Palmer et al. (Palmer et al., 2005), the question remains how ${ }^{44} \mathrm{Sc}$ fits into the sequence of these radionuclides in terms of imaging resolution. In the present study, five common PET nuclides $\left({ }^{11} \mathrm{C},{ }^{18} \mathrm{~F},{ }^{68} \mathrm{Ga},{ }^{64} \mathrm{Cu}\right.$ and $\left.{ }^{89} \mathrm{Zr}\right)$ were investigated with regard to their relative image resolution using small-animal PET for comparison with the results obtained with ${ }^{44} \mathrm{Sc}$. For this purpose, Derenzo phantoms were used, along with a GE Healthcare eXplore Vista small-animal PET scanner. 


\section{Experimental arrangement}

\subsection{Production of ${ }^{18} \mathrm{~F},{ }^{11} \mathrm{C},{ }^{68} \mathrm{Ga},{ }^{44} \mathrm{Sc},{ }^{64} \mathrm{Cu}$ and ${ }^{89} \mathrm{Zr}$}

No-carrier-added $\left[{ }^{18} \mathrm{~F}\right]$ fluorine was produced via the ${ }^{18} \mathrm{O}(\mathrm{p}, \mathrm{n}){ }^{18} \mathrm{~F}$ nuclear reaction by irradiation of enriched ${ }^{18} \mathrm{O}$-water at a Cyclone 18/9 cyclotron (18 MeV; IBA, Ottignies-Louvain-la-Neuve, Belgium) at CRS, ETH Zurich (Fischer et al., 2012). ${ }^{11} \mathrm{C}$ was produced at the same cyclotron via the ${ }^{14} \mathrm{~N}(\mathrm{p}, \alpha){ }^{11} \mathrm{C}$ nuclear reaction in the form of $\left[{ }^{11} \mathrm{C}\right] \mathrm{CO}_{2}$ (Mu et al., 2013a). ${ }^{68} \mathrm{Ga}$ was obtained from a ${ }^{68} \mathrm{Ge} /{ }^{68} \mathrm{Ga}-$ generator IGG100-50 (Eckert \& Ziegler, Berlin, Germany) (Mu et al., 2013b). ${ }^{64} \mathrm{Cu}$ was produced via the ${ }^{64} \mathrm{Ni}(\mathrm{p}, \mathrm{n}){ }^{64} \mathrm{Cu}$ nuclear reaction and ${ }^{89} \mathrm{Zr}$ was produced via the ${ }^{89} \mathrm{Y}(\mathrm{p}, \mathrm{n}){ }^{89} \mathrm{Zr}$ nuclear reaction at the Injector II cyclotron facility at CRS, PSI Villigen (Hohn et al., 2008). ${ }^{44} \mathrm{Sc}$ was produced at the same research cyclotron, via the ${ }^{44} \mathrm{Ca}(\mathrm{p}, \mathrm{n}){ }^{44} \mathrm{Sc}$ nuclear reaction as previously reported by our group (Müller et al., 2013; van der Meulen et al., 2015). The quantity of the radioactivity used for phantom studies was determined in dose calibrators (ISOMED 2010, Nuclear-Medizintechnik, Dresden GmbH or VDC-505, Veenstra Instruments, The Netherlands). The factors for non-standard nuclides, such as for instance ${ }^{44} \mathrm{Sc}$, were determined based on exact activity measurements on a N-type high-purity germanium (HPGe) coaxial detector (EURISYSMESURES, France) using Ortec InterWinner software version 5.0.

The radionuclidic purity of all investigated radionuclides was $>99 \% .{ }^{44} \mathrm{Sc}$ comprised traces of ${ }^{44 \mathrm{~m}} \mathrm{Sc}$ $(<1 \%)$ (Müller et al., 2013) and ${ }^{88} \mathrm{Zr}(<1 \%)$ was present as a radionuclidic impurity in the ${ }^{89} \mathrm{Zr}$ solution (Hohn et al., 2008).

\subsection{Preparation of the phantoms}

Derenzo phantoms with a diameter of $\mathrm{D}=19.5 \mathrm{~mm}$, a height of $\mathrm{H}=15.0 \mathrm{~mm}$ and holes with diameters ranging from $0.8 \mathrm{~mm}$ to $1.3 \mathrm{~mm}$ in $0.1 \mathrm{~mm}$-steps were used for this study (Supplementary Data Fig. S1). The phantoms were filled (total volume of $600 \mu \mathrm{L}$ ) with the aqueous solution of the desired nuclide and ethanol (25 Vol\%) to enable proper filling of the capillaries. 


\subsection{PET imaging}

All PET scans were performed with the same preclinical scanner, a small-animal eXplore VISTA PET/CT (GE Healthcare Sedecal, Spain) at an energy window of 250-700 keV. The features and characteristics of this kind of preclinical PET scanner have been reported in detail by Wang et al. (Wang et al., 2006). Based on the measured count rate (counts/s) of each radionuclide, the required scan time for $\sim 60$ Mio coincidences was determined. The 2-dimensional ordered-subset expectation maximization (2D-OSEM) algorithm was used for the reconstruction of the PET data and the images were prepared using VivoQuant image post-processing program software (version 2.00, Bioscan Inc., U.S.).

\subsection{Quantification of the relative resolution by determination of full-width at half-maximum (FWHM)}

With the "cropping" function of the VivoQuant software, one representative single transversal section was selected at three different depths of the phantom. A line was drawn through the center point of the radioactive spot obtained from the $1.3 \mathrm{~mm}$-hole of the Derenzo phantom (Fig. 1A) and then the “distance/annotation" function of the VivoQuant software was applied to produce an intensity plot of the selected profile. The plot data were saved as a $c s v$-file for export. The data were transferred to Origin 2015, which allowed normalization by background subtraction. More specifically, this means that the intensity plot line was drawn from dark-to-dark and the lowest value of the start and end points was set to zero. A cubic spline was then fitted through the data and the full-width at halfmaximum (FWHM) was determined (Fig. 1B). The listed values in Table 2 indicate the average and standard deviation of 3 determinations for FWHM based on the 3 different sections of each phantom scan. One section of each phantom scan is shown in figure 2. In order to obtain an optimal image, the intensity of the color scale was adjusted manually.

Figure 1 


\section{Results and discussion}

\subsection{Theoretical spatial resolution}

Spatial resolution is a parameter describing the system's ability to distinguish between two radioactive sources in an image. In theory, this parameter is expressed as the full-width at half-maximum (FWHM) and is specific for a particular PET system (Palmer et al., 2005). For this study, scannerspecific parameters refer to the eXplore VISTA PET scanner which was used for all phantom scans (Wang et al., 2006). The main remaining parameter responsible for the spatial resolution of a PET image is the positron range, which is dependent on the positron energy (Rahmim and Zaidi, 2008). Small positron energy results in an improved image quality, whereas high positron energy will degrade the spatial resolution, especially in small-animal PET imaging (Liu and Laforest, 2009). Given that the $1.3 \mathrm{~mm}$ diameter spot of the Derenzo phantom is not necessarily a bona fide point source in terms of the small scanner diameter, only a relative resolution assessment can be made, with a sequence expectation of increasing resolution of ${ }^{68} \mathrm{Ga}<{ }^{89} \mathrm{Zr}<{ }^{11} \mathrm{C}<{ }^{64} \mathrm{Cu}<{ }^{18} \mathrm{~F}$, with ${ }^{44} \mathrm{Sc}$ expected to be placed between ${ }^{68} \mathrm{Ga}$ and ${ }^{89} \mathrm{Zr}$.

\subsection{PET scans of the phantoms}

In order to allow comparison of the PET image quality obtained with ${ }^{11} \mathrm{C},{ }^{18} \mathrm{~F},{ }^{64} \mathrm{Cu},{ }^{89} \mathrm{Zr},{ }^{44} \mathrm{Sc}$ and ${ }^{68} \mathrm{Ga}$ the phantoms were scanned for the required time period $(6-30 \mathrm{~min})$ to acquire $\sim 60$ Mio coincidences (range from 49-65 Mio) (Table S1, Supplementary Data).

\subsection{Comparison of the PET image quality obtained with different nuclides}

The PET images of the Derenzo phantoms obtained with each radionuclide are shown in Figure 2. Visual comparison of the PET images revealed the best resolution for ${ }^{18} \mathrm{~F}$ and ${ }^{64} \mathrm{Cu}$, followed by ${ }^{11} \mathrm{C}$ and ${ }^{89} \mathrm{Zr}$ and ${ }^{68} \mathrm{Ga}$, which showed clearly lower resolution. From a visual perspective, the resolution obtained with ${ }^{44} \mathrm{Sc}$ was between ${ }^{68} \mathrm{Ga}$ and ${ }^{89} \mathrm{Zr}$. Determination of FWHM values for ${ }^{18} \mathrm{~F},{ }^{64} \mathrm{Cu},{ }^{11} \mathrm{C},{ }^{89} \mathrm{Zr}$ and ${ }^{68} \mathrm{Ga}$ for a hole-diameter of $1.3 \mathrm{~mm}$ revealed values which were in excellent agreement with the results previously predicted by theoretical calculations of Palmer et al. (Palmer et al., 2005). In this 
study, the sequence of resolutions was determined with ${ }^{18} \mathrm{~F}$ on top, followed by ${ }^{64} \mathrm{Cu},{ }^{89} \mathrm{Zr},{ }^{11} \mathrm{C}$ and ${ }^{68} \mathrm{Ga}$ (Table 2). The value for ${ }^{44} \mathrm{Sc}$ which has not been investigated previously revealed a resolution between those of ${ }^{68} \mathrm{Ga}$ and ${ }^{89} \mathrm{Zr}$. The visual findings and the determined value for the FWHM of ${ }^{44} \mathrm{Sc}$ are in agreement with the expectations according to the positron energies of ${ }^{44} \mathrm{Sc}$ and the tested radionuclides, resulting in ${ }^{18} \mathrm{~F}>{ }^{64} \mathrm{Cu}>{ }^{11} \mathrm{C}>{ }^{89} \mathrm{Zr}>{ }^{44} \mathrm{Sc}>{ }^{68} \mathrm{Ga}$.

\section{Figure 2}

Table 2

\section{Conclusion}

This phantom study enabled the determination of the preclinical PET imaging resolution for ${ }^{44} \mathrm{Sc}$ in comparison with five frequently-used PET radionuclides. In agreement with decreasing positron energies, we found an increasing image resolution in the sequence of ${ }^{68} \mathrm{Ga}<{ }^{44} \mathrm{Sc}<{ }^{89} \mathrm{Zr}<{ }^{11} \mathrm{C}<{ }^{64} \mathrm{Cu}<$ ${ }^{18} \mathrm{~F}$. This study allowed visual presentation of the imaging characteristics of ${ }^{44} \mathrm{Sc}$ as it would be theoretically expected, based on its decay properties. Importantly, the experimental values for the FWHM of the investigated radionuclides were in excellent agreement with the theoretical predictions of Palmer et al. (Palmer et al., 2005). 


\section{Acknowledgments}

The authors thank Walter Hirzel (PSI), Alexander Sommerhalder (PSI), Martin Hungerbühler (PSI), Dr. Linjing Mu (USZ), Dr. Thomas Betzel (ETH), Bruno Mancosu (ETH), Lukas Dialer (ETH), Martina Dragic (ETH) and Claudia Keller (ETH) for technical assistance. The research was financially supported by the Swiss National Science Foundation (PZ00P3_138834) and the Swiss Cancer League (KLS-02762-02-2011). 


\section{References}

Anderson, C.J., Ferdani, R., 2009. Copper-64 radiopharmaceuticals for PET imaging of cancer: advances in preclinical and clinical research. Cancer Biother Radiopharm 24, 379-393.

Basu, S., Alavi, A., 2008. Unparalleled contribution of ${ }^{18}$ F-FDG PET to medicine over 3 decades. J Nucl Med 49, 17N-21N, 37N.

Dijkers, E.C., Oude Munnink, T.H., Kosterink, J.G., Brouwers, A.H., Jager, P.L., de Jong, J.R., van Dongen, G.A., Schroder, C.P., Lub-de Hooge, M.N., de Vries, E.G., 2010. Biodistribution of ${ }^{89} \mathrm{Zr}$ trastuzumab and PET imaging of HER2-positive lesions in patients with metastatic breast cancer. Clin Pharmacol Ther 87, 586-592.

Eiber, M., Maurer, T., Souvatzoglou, M., Beer, A.J., Ruffani, A., Haller, B., Graner, F.P., Kubler, H., Haberhorn, U., Eisenhut, M., Wester, H.J., Gschwend, J.E., Schwaiger, M., 2015. Evaluation of Hybrid ${ }^{68}$ Ga-PSMA ligand PET/CT in 248 patients with biochemical recurrence after radical prostatectomy. J Nucl Med 56, 668-674.

Fischer, C.R., Müller, C., Reber, J., Müller, A., Kramer, S.D., Ametamey, S.M., Schibli, R., 2012. $\left[{ }^{18}\right.$ F]fluoro-deoxy-glucose folate: a novel PET radiotracer with improved in vivo properties for folate receptor targeting. Bioconjug Chem 23, 805-813.

Gabriel, M., Decristoforo, C., Kendler, D., Dobrozemsky, G., Heute, D., Uprimny, C., Kovacs, P., Von Guggenberg, E., Bale, R., Virgolini, I.J., 2007. ${ }^{68}$ Ga-DOTA-Tyr 3 -octreotide PET in neuroendocrine tumors: comparison with somatostatin receptor scintigraphy and CT. J Nucl Med 48, 508-518.

Hohn, A., Zimmermann, K., Schaub, E., Hirzel, W., Schubiger, P.A., Schibli, R., 2008. Production and separation of "non-standard" PET nuclides at a large cyclotron facility: the experiences at the Paul Scherrer Institute in Switzerland. Q J Nucl Med Mol Imaging 52, 145-150.

Krajewski, S., Cydzik, I., Abbas, K., Bulgheroni, A., Simonelli, F., Holzwarth, U., Bilewicz, A., 2013. Cyclotron production of ${ }^{44} \mathrm{Sc}$ for clinical application. Radiochim. Acta 101, 333-338.

Kramer-Marek, G., Capala, J., 2012. Can PET imaging facilitate optimization of cancer therapies? Curr Pharm Des 18, 2657-2669. 
Laforest, R., Liu, X., 2008. Image quality with non-standard nuclides in PET. Q J Nucl Med Mol Imaging 52, 151-158.

Liu, X., Laforest, R., 2009. Quantitative small animal PET imaging with nonconventional nuclides. Nucl Med Biol 36, 551-559.

Mittra, E., Quon, A., 2009. Positron emission tomography/computed tomography: the current technology and applications. Radiol Clin N Am 47, 147-160.

Mu, L., Bieri, D., Slavik, R., Drandarov, K., Muller, A., Cermak, S., Weber, M., Schibli, R., Kramer, S.D., Ametamey, S.M., 2013a. Radiolabeling and in vitro /in vivo evaluation of N-(1-adamantyl)-8methoxy-4-oxo-1-phenyl-1,4-dihydroquinoline-3-carboxamide as a PET probe for imaging cannabinoid type 2 receptor. J Neurochem 126, 616-624.

Mu, L., Hesselmann, R., Oezdemir, U., Bertschi, L., Blanc, A., Dragic, M., Loffler, D., Smuda, C., Johayem, A., Schibli, R., 2013b. Identification, characterization and suppression of side-products formed during the synthesis of high dose ${ }^{68}$ Ga-DOTA-TATE. Appl Radiat Isot 76, 63-69.

Müller, C., Bunka, M., Reber, J., Fischer, C., Zhernosekov, K., Türler, A., Schibli, R., 2013. Promises of cyclotron-produced ${ }^{44} \mathrm{Sc}$ as a diagnostic match for trivalent $\beta^{-}$-emitters: In vitro and in vivo study of a ${ }^{44}$ Sc-DOTA-folate conjugate. J Nucl Med 54, 2168-2174.

Palmer, M.R., Zhu, X., Parker, A., 2005. Modeling and simulation of positron range effects for high resolution PET imaging IEEE Transactions on Nuclear Science 52, 1391-1395.

Rahmim, A., Zaidi, H., 2008. PET versus SPECT: strengths, limitations and challenges. Nucl Med Commun 29, 193-207.

Roesch, F., 2012. Scandium-44: benefits of a long-lived PET radionuclide available from the ${ }^{44} \mathrm{Ti} /{ }^{44} \mathrm{Sc}$ generator system. Curr Radiopharm 5, 187-201.

Severin, G.W., Engle, J.W., Valdovinos, H.F., Barnhart, T.E., Nickles, R.J., 2012. Cyclotron produced ${ }^{44 g} \mathrm{Sc}$ from natural calcium. Appl Radiat Isot 70, 1526-1530.

van der Meulen, N.P., Bunka, M., Domnanich, K.A., Müller, C., Haller, S., Vermeulen, C., Türler, A., Schibli, R., 2015. Cyclotron production of ${ }^{44}$ Sc: From bench to bedside. Nucl Med Biol 42, 745-751. Wang, Y., Seidel, J., Tsui, B.M., Vaquero, J.J., Pomper, M.G., 2006. Performance evaluation of the GE healthcare eXplore VISTA dual-ring small-animal PET scanner. J Nucl Med 47, 1891-1900. 


\section{Tables}

\section{Table 1}

Decay properties of PET nuclides used in this study. Data are based on the chart of nuclides of the National Nuclear Data Center (http://www.nndc.bnl.gov/chart/).

\begin{tabular}{|c|c|c|c|c|c|c|}
\hline Radionuclide & Half-life & $\begin{array}{c}\mathrm{E} \beta^{+}{ }_{\text {average }} \\
{[\mathrm{keV}]}\end{array}$ & $\begin{array}{l}\mathrm{I} \beta^{+} \\
{[\%]}\end{array}$ & $\begin{array}{c}\mathrm{E} \gamma \\
{[\mathrm{keV}]}\end{array}$ & $\begin{array}{c}\mathrm{I} \gamma \\
{[\%]}\end{array}$ & Production route \\
\hline${ }^{18} \mathrm{~F}$ & $110 \mathrm{~min}$ & 250 & 96.7 & - & - & ${ }^{18} \mathrm{O}(\mathrm{p}, \mathrm{n}){ }^{18} \mathrm{~F}$ \\
\hline${ }^{64} \mathrm{Cu}$ & $12.7 \mathrm{~h}$ & 278 & 17.6 & 1346 & 0.48 & ${ }^{64} \mathrm{Ni}(\mathrm{p}, \mathrm{n}){ }^{64} \mathrm{Cu}$ \\
\hline${ }^{11} \mathrm{C}$ & $20 \mathrm{~min}$ & 386 & 99.8 & - & - & ${ }^{14} \mathrm{~N}(\mathrm{p}, \alpha){ }^{11} \mathrm{C}$ \\
\hline${ }^{89} \mathrm{Zr}$ & $78.4 \mathrm{~h}$ & 396 & 22.7 & $\begin{array}{c}909 \\
1713\end{array}$ & $\begin{array}{l}99.0 \\
0.75\end{array}$ & ${ }^{89} \mathrm{Y}(\mathrm{p}, \mathrm{n}){ }^{89} \mathrm{Zr}$ \\
\hline${ }^{44} \mathrm{Sc}$ & $3.97 \mathrm{~h}$ & 632 & 94.3 & $\begin{array}{l}1157 \\
1499\end{array}$ & $\begin{array}{l}99.9 \\
0.91\end{array}$ & $\begin{array}{c}{ }^{44} \mathrm{Ti} /{ }^{44} \mathrm{Sc} \text {-generator } \\
{ }^{44} \mathrm{Ca}(\mathrm{p}, \mathrm{n}){ }^{44} \mathrm{Sc}\end{array}$ \\
\hline${ }^{68} \mathrm{Ga}$ & $68 \mathrm{~min}$ & 830 & 88.9 & 1077 & 3.2 & ${ }^{68} \mathrm{Ge} /{ }^{68} \mathrm{G}$-generator \\
\hline
\end{tabular}

\section{Table 2}

Full-width at half-maximum (FWHM) published by Palmer et al. and values determined for phantom hole-diameters of $1.3 \mathrm{~mm}$ for each radionuclide from 3 different sections of the PET scan.

\begin{tabular}{cccc}
\hline Radionuclide & $\begin{array}{c}\mathrm{E}^{+}{ }_{\text {average }}[\mathrm{keV}] \\
(\text { nudat })\end{array}$ & $\begin{array}{c}\text { FWHM [mm] } \\
(\text { Palmer et al., 2005) }\end{array}$ & $\begin{array}{c}\text { FWHM [mm] } \\
\text { This work }\end{array}$ \\
\hline${ }^{18} \mathrm{~F}$ & 250 & 1.67 & $1.67 \pm 0.02$ \\
\hline${ }^{64} \mathrm{Cu}$ & 278 & 1.71 & $1.72 \pm 0.03$ \\
\hline${ }^{11} \mathrm{C}$ & 386 & 1.88 & $1.80 \pm 0.00$ \\
\hline${ }^{89} \mathrm{Zr}$ & 396 & 1.91 & $1.98 \pm 0.05$ \\
\hline${ }^{44} \mathrm{Sc}$ & $\mathbf{6 3 2}$ & n.d. & $\mathbf{2 . 3 0 \pm 0 . 1 2}$ \\
\hline${ }^{68} \mathrm{Ga}$ & 830 & 2.74 & $2.48 \pm 0.22$ \\
\hline
\end{tabular}




\section{Figure Legends}

Fig. 1. (A) Scheme of the holes alignment of the Derenzo phantom. The $1.3 \mathrm{~mm}$ hole which was used for determination of the full-width at half-maximum (FWHM) is indicated in red. (B) Cubic spline fitted for the intensity curve of the $1.3 \mathrm{~mm}$ hole to allow determination of the FWHM.

Fig. 2. Transversal sections of PET scans of Derenzo phantoms filled with ${ }^{18} \mathrm{~F},{ }^{64} \mathrm{Cu},{ }^{11} \mathrm{C},{ }^{89} \mathrm{Zr},{ }^{44} \mathrm{Sc}$ and ${ }^{68} \mathrm{Ga}$. The PET scans were acquired with an energy window of $250-700 \mathrm{keV}$. The scans lasted for $6-30$ min, allowing acquisition of a total number of $\sim 60$ Mio total coincidences. 


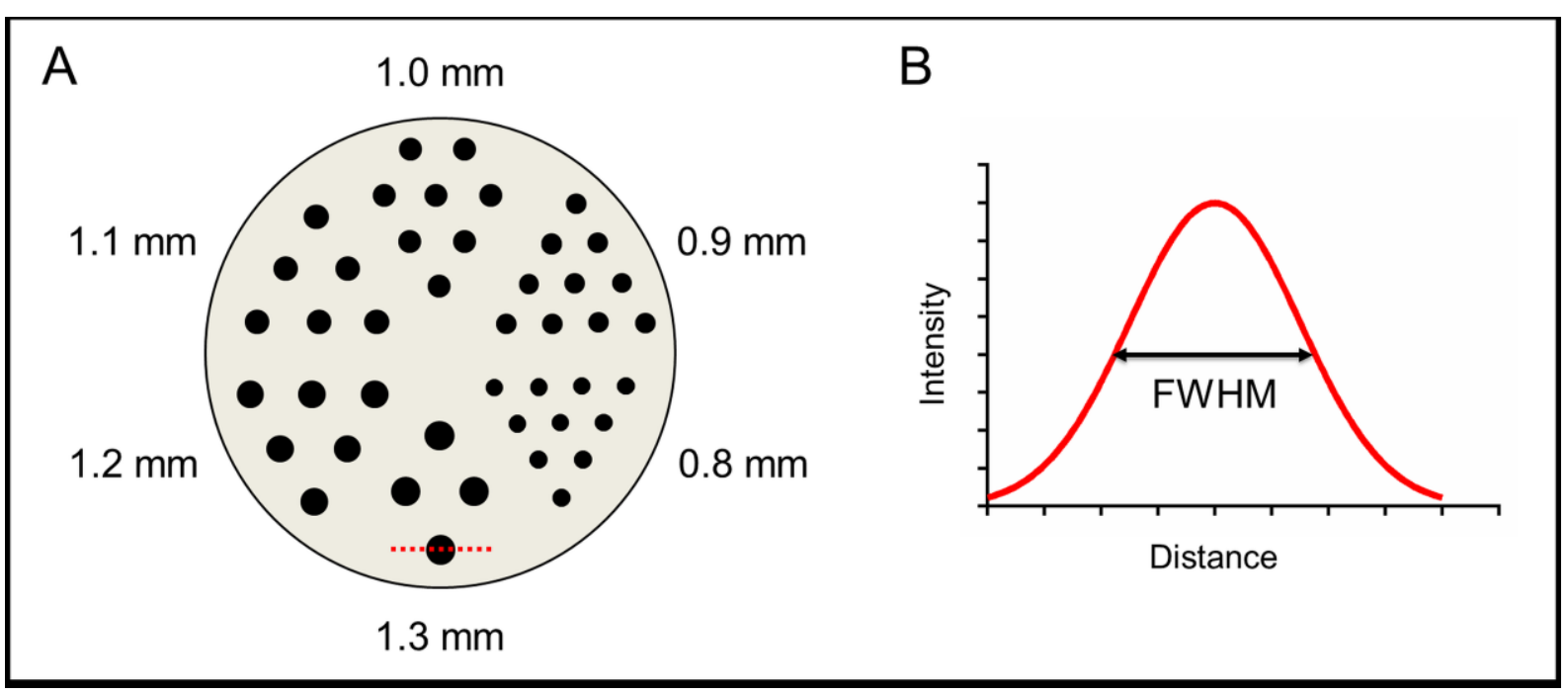




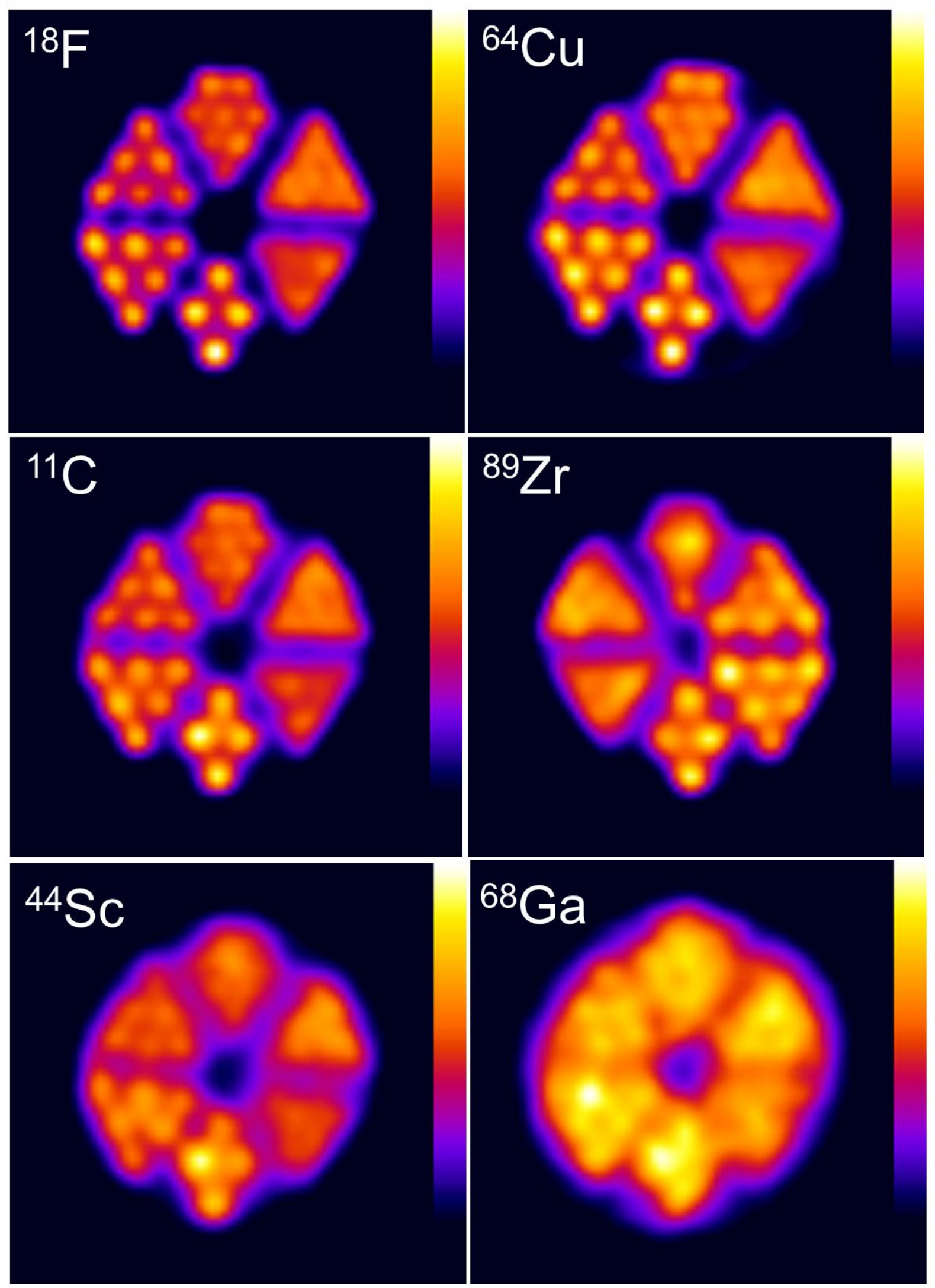

